\title{
Airway closure, more harmful than atelectasis in intensive care?
}

\author{
Göran Hedenstierna ${ }^{1 *}$, Lu Chen ${ }^{2,3}$ and Laurent Brochard ${ }^{2,3}$
}

() 2020 The Author(s)

Since the mid-1980s, atelectasis has been demonstrated during anesthesia in lung healthy subjects [1] and in intensive care patients suffering from acute respiratory failure and requiring ventilator support [2]. In the latter case, there are additional causes of airless lung tissues, such as alveolar fluid filling and consolidation. The airless tissue is still perfused, causing a shunt with impairment of the oxygenation of blood. Moreover, cyclic opening and closing of alveolar units may harm the tissue and trigger an inflammatory reaction [3]. This is well known and has been considered a major morphological disturbance in the mechanically ventilated subject. However, there are indirect observations of another morphological disturbance, some airways that are either continuously closed or cyclically opening and closing during the ventilation. This airway closure is a normal phenomenon, although of small magnitude and seldom continuous, in awake, spontaneously breathing healthy subjects. It begins in dependent lung regions and spreads out to include additional airways during the continuing expiration [4]. However, during anesthesia and in acute respiratory failure airway closure is much more marked and may be of similar importance as alveolar airlessness in impeding lung function, and promoting inflammation $[5,6]$.

Airway closure was initially demonstrated (or rather suggested) by single breath tracer gas recordings [4]. Recently, airway closure was also visually demonstrated by synchrotron radiation technique (Fig. 1) displaying different patterns of the closure phenomenon [7]. One was complete closure of dependent, peripheral airways, in line with what has been assumed since long. Another

*Correspondence: goran.hedenstierna@medsci.uu.se

${ }^{1}$ Hedenstierna Laboratory, Department of Medical Sciences, University Hospital, Uppsala University, Entr 40:2, 75185 Uppsala, Sweden

Full author information is available at the end of the article was repeated closures of the airway so that gas was trapped within a distance of the airway. This suggests a more complicated background for airway closure, not only trans-airway pressure but also changes in surface tension, liquid distribution within the airway and interdependence between units $[7,8]$.

Airway closure increases with increasing age, a consequence of loss of elastic tissue in the lung that may produce a positive pleural pressure in dependent regions [4]. Decrease in resting lung volume, functional residual capacity (FRC), promotes airway closure [4]. Factors that in combination reduce FRC, like anesthesia, age, obesity and head down positions for surgery will all increase likelihood for airway closure. Recently, complete airway closure has been suggested in ARDS [6]. In these patients, lung inflation starts when airway pressure reaches a critical level of opening pressure [9]. This has been mistaken in the past as being a lower inflection point indicating recruitment of a collapsed lung. This phenomenon may be due to collapse of airways at end-expiration. The mechanism and actual location of this collapse is unknown and may not be identical to the classic airway closure that is related to transpulmonary pressure and, thus, is gravitationally oriented [4]. One possible, still speculative, mechanism is that the trachea is compressed by surrounding tissue that may be increased in obesity and/or displaced by body position, and by relaxation of tracheal smooth muscle [10]. Surfactant depletion may add to both central and peripheral airway instability and cause widespread closure and injury, also in distal airways $[7,8]$. As a consequence, alveoli remain inflated at endexpiration. A recent study of ARDS found one-third of patients depicting complete airway closure with reopening anywhere between 6 and $20 \mathrm{~cm} \mathrm{H}_{2} \mathrm{O}$ [11]. Complete airway closure has also been reported in $22 \%$ of obese anesthetized patients with normal lungs [12]. In patients with ARDS, obesity increases the incidence of airway

\section{Springer}


A
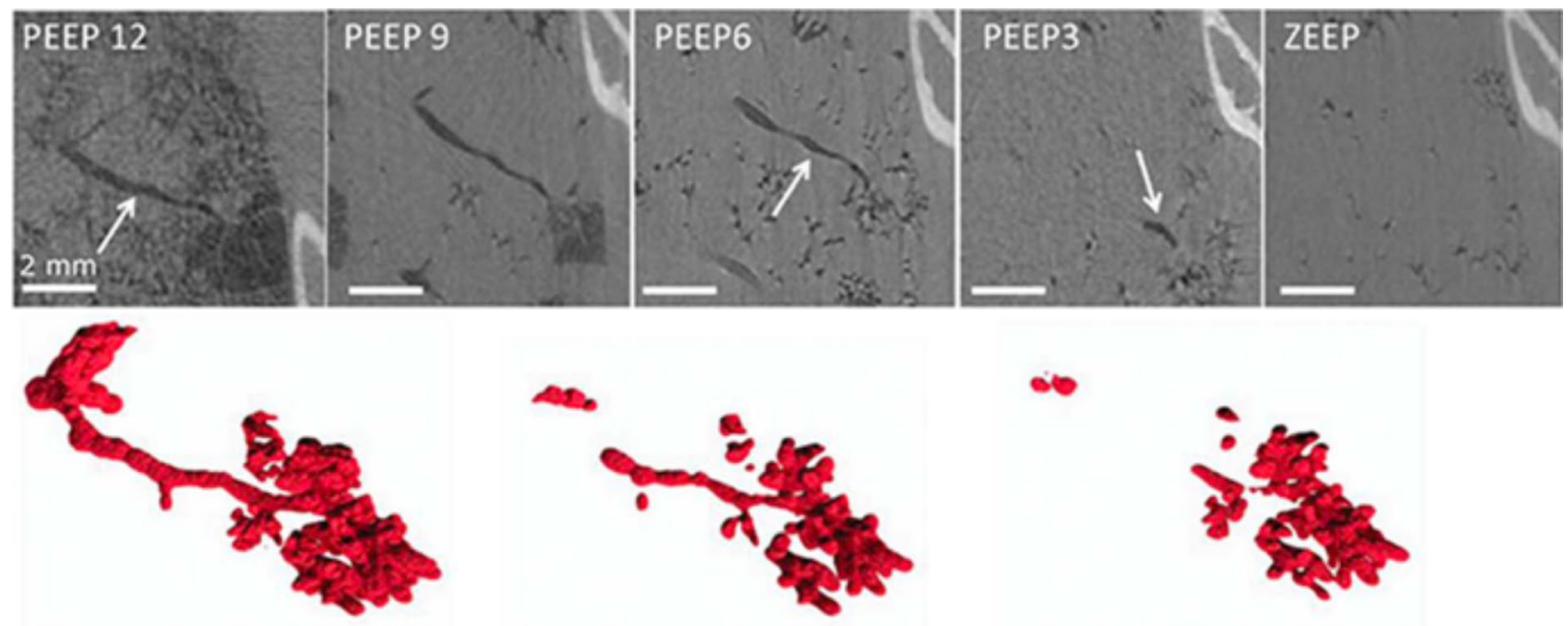

PEEP 12

PEEP6

PEEP3

B

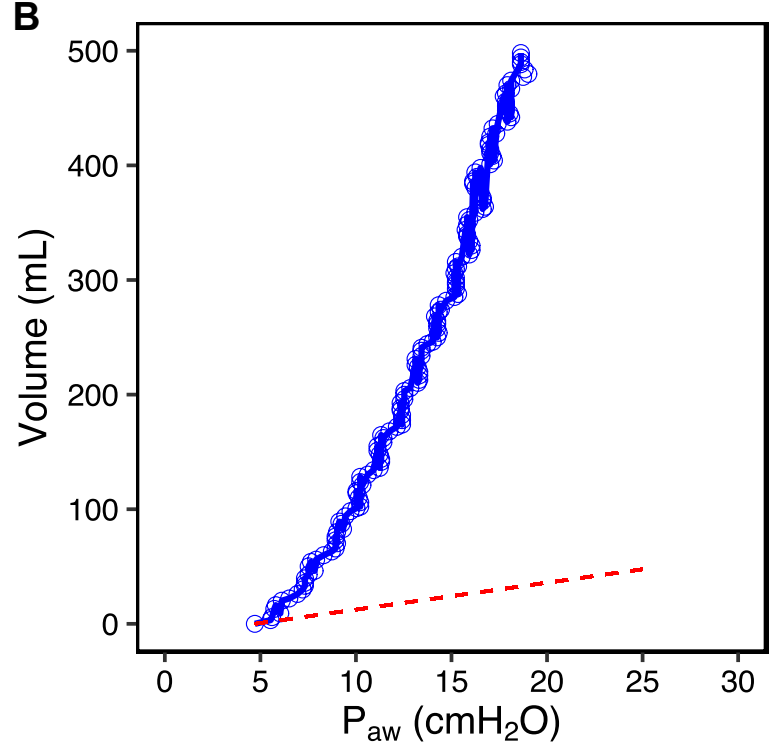

C

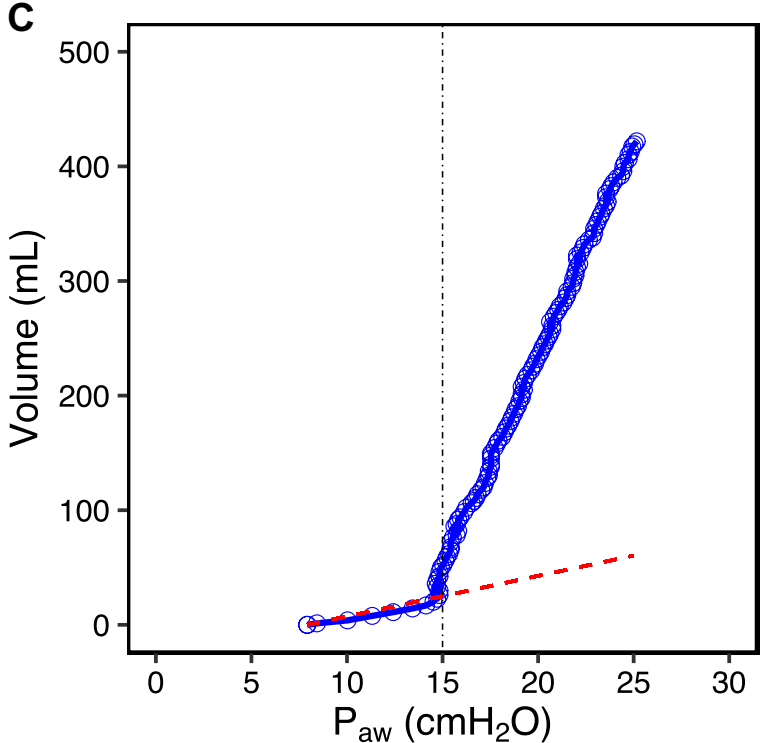

Fig. 1 a Study of airway closure in a rabbit whole-lung lavage and injurious ventilation model, using synchrotron radiation technique. The image is an iso-gravitational cut through the lung with the rabbit in an upright position. Note that small airways, 18th of 21 generations, are open when PEEP is $12 \mathrm{~cm} \mathrm{H} \mathrm{H}_{2} \mathrm{O}$, but begin to close with PEEP 6 and that most small airways are closed at PEEP 3. Alveoli remain open but it may be anticipated that they close after some time, in particular if ventilation is with 100\% oxygen [7]. b Low-flow inflation pressure-volume (P-V) curve from a patient without complete airway closure. P-V curve of the patient (blue) and the occluded circuit (red) separate immediately and cardiac oscillations can be seen throughout the whole P-V curve [13]. c Low-flow inflation P-V curve from a patient with complete airway closure. P-V curve of the patient (blue) superimposed to that of the occluded circuit (red) until airway pressure exceeded a critical level—airway opening pressure (black line at $15 \mathrm{~cm} \mathrm{H}_{2} \mathrm{O}$ ). After this, cardiac oscillations can be seen on the P-V curve [13]

closure (more than $65 \%$ of patients with BMI $>39 \mathrm{~kg} / \mathrm{m}^{2}$ ) [13]. Interestingly while auto-PEEP (or intrinsic PEEP) is easily eliminated by prolonging expiratory time, the level of airway opening pressure is not influenced by the duration of expiration and remains at a very reproducible level [11]. The absence of ventilation below this airway opening pressure has been visualized by electric impedance tomography [9].

There are at least four major consequences of airway closure. Firstly, a continuously closed or briefly open airway will promote atelectasis because of absent or poor ventilation, alveolar gas being sucked up by the capillary 
blood. Indeed, the atelectasis during anesthesia is almost always caused by airway closure [1]. The use of high inspired oxygen concentration speeds up the atelectasis formation because of rapid absorption of oxygen in the alveoli, whereas nitrogen in the alveoli will prevent or slow down atelectasis formation.

Secondly, the impaired ventilation by cyclic airway closure causes a ventilation/perfusion mismatch with impairment of oxygenation of blood. In addition, continuous airway closure promotes alveolar collapse, as said above, that causes a shunt and impairment of arterial oxygenation.

Thirdly, there are animal experiments suggesting that the beginning of an inflammatory reaction in the lung is not in dependent, collapsed/airless regions, nor in the uppermost, possibly over-aerated regions, but in a zone somewhere in the middle of the lung [14]. This zone is mostly poorly aerated, suggesting cyclic airway closure. Such cyclic closure results in a physical stress to the airway wall, opening and closing where surface forces have to be overcome and where the wall may suffer from damage [14]. Importantly, whereas atelectasis results in alveolar injury mostly in aerated regions, the repetitive opening and closing of distal airways occur also in lung regions that are atelectatic [15].

Fourth, the presence of airway closure makes measurement of alveolar pressure at the airway opening impossible or unreliable. Wrong estimates of driving pressure and compliance happen in case of airway closure because the alveolar pressure is not measured at the airway opening even after an occlusion [13].

A simple technique to assess complete airway closure is by using the low-flow inflation pressure-volume curve pattern (Fig. 1). The presence of low inflection point associated with, in the initial part of the curve, the absence of cardiac oscillations and very low compliance, close to the $2.5 \mathrm{~mL} / \mathrm{cm} \mathrm{H}_{2} \mathrm{O}$ of an occluded breathing circuit, is suggestive of complete airway closure [11]. When pressure exceeds the low inflection point, cardiac oscillations appear and compliance dramatically increases as compared to the initial part of the curve. Even simpler is the use of a pressure-time curve using a low-flow inflation (see a video on rtmaven.com; this can be done on any ICU ventilator). This low inflection point corresponds to the pressure needed to start inflating the lungs and reflects the airway opening pressure. Setting PEEP at the level of this airway opening pressure is recommended to avoid or minimize the repetitive opening and closure of small airways.

In summary, airway closure is a frequent finding in anesthesia and intensive care and is a major cause of lung dysfunction and even inflammation. It is also a major cause of atelectasis. Its detection and prevention are important steps in optimizing ventilator support.

\begin{abstract}
Author details
${ }^{1}$ Hedenstierna Laboratory, Department of Medical Sciences, University Hospital, Uppsala University, Entr 40:2, 75185 Uppsala, Sweden. ${ }^{2}$ Keenan Research Centre, Li Ka Shing Knowledge Institute, St. Michael's Hospital, Toronto, Canada. ${ }^{3}$ Interdepartmental Division of Critical Care Medicine, University of Toronto, Toronto, Canada.
\end{abstract}

\section{Acknowledgement}

Open access funding provided by Uppsala University.

Compliance with ethical standards

Conflicts of interest

The authors declare that they have no conflicts of interest.

Ethical approval

The authors declare that there is no ethical concern with the study.

\section{Open Access}

This article is licensed under a Creative Commons Attribution-NonCommercial 4.0 International License, which permits any non-commercial use, sharing, adaptation, distribution and reproduction in any medium or format, as long as you give appropriate credit to the original author(s) and the source, provide a link to the Creative Commons licence, and indicate if changes were made. The images or other third party material in this article are included in the article's Creative Commons licence, unless indicated otherwise in a credit line to the material. If material is not included in the article's Creative Commons licence and your intended use is not permitted by statutory regulation or exceeds the permitted use, you will need to obtain permission directly from the copyright holder. To view a copy of this licence, visit http://creativecommons.org/licen ses/by-nc/4.0/.

\section{Publisher's Note}

Springer Nature remains neutral with regard to jurisdictional claims in published maps and institutional affiliations.

Received: 30 April 2020 Accepted: 26 May 2020

Published online: 4 June 2020

\section{References}

1. Hedenstierna G, Tokics L, Scaramuzzo G, Rothen HU, Edmark L, Ohrvik $J$ (2019) Oxygenation impairment during anesthesia: influence of age and body weight. Anesthesiology 131(1):46-57. https://doi.org/10.1097/ ALN.0000000000002693

2. Gattinoni L, Caironi P, Cressoni M, Chiumello D, Ranieri VM, Quintel M, Russo S, Patroniti N, Cornejo R, Bugedo G (2006) Lung recruitment in patients with the acute respiratory distress syndrome. N Engl J Med 354(17):1775-1786. https://doi.org/10.1056/NEJMoa052052

3. Rouby JJ, Lherm T, Martin de Lassale E, Poete P, Bodin L, Finet JF, Callard P, Viars P (1993) Histologic aspects of pulmonary barotrauma in critically ill patients with acute respiratory failure. Intensive Care Med 19(7):383-389. https://doi.org/10.1007/bf01724877

4. Milic-Emili J, Torchio R, D'Angelo E (2007) Closing volume: a reappraisal (1967-2007). Eur J Appl Physiol 99(6):567-583. https://doi.org/10.1007/ s00421-006-0389-0

5. Rothen HU, Sporre B, Engberg G, Wegenius G, Hedenstierna G (1998) Airway closure, atelectasis and gas exchange during general anaesthesia. Br J Anaesth 81(5):681-686. https://doi.org/10.1093/bja/81.5.681

6. Chen L, Del Sorbo L, Grieco DL, Shklar O, Junhasavasdikul D, Telias I, Fan E, Brochard L (2018) Airway closure in acute respiratory distress syndrome: an underestimated and misinterpreted phenomenon. Am J Respir Crit Care Med 197(1):132-136. https://doi.org/10.1164/rccm.201702-0388LE 
7. Broche L, Pisa P, Porra L, Degrugilliers L, Bravin A, Pellegrini M, Borges JB, Perchiazzi G, Larsson A, Hedenstierna G, Bayat S (2019) Individual airway closure characterized in vivo by phase-contrast CT imaging in injured rabbit lung. Crit Care Med 47(9):e774-e781. https://doi.org/10.1097/ CCM.0000000000003838

8. Coudroy R, Lu C, Chen L, Demoule A, Brochard L (2019) Mechanism of airway closure in acute respiratory distress syndrome: a possible role of surfactant depletion. Intensive Care Med 45(2):290-291. https://doi. org/10.1007/s00134-018-5501-5

9. Sun XM, Chen GQ, Zhou YM, Yang YL, Zhou JX (2018) Airway closure could be confirmed by electrical impedance tomography. Am J Respir Crit Care Med 197(1):138-141. https://doi.org/10.1164/rccm.20170 6-1155LE

10. Richardson J, Beland J (1976) Nonadrenergic inhibitory nervous system in human airways. J Appl Physiol 41(5 Pt. 1):764-771. https://doi. org/10.1152/jappl.1976.41.5.764

11. Chen L, Del Sorbo L, Grieco DL, Junhasavasdikul D, Rittayamai N, Soliman I, Sklar MC, Rauseo M, Ferguson ND, Fan E, Richard JM, Brochard L (2020) Potential for lung recruitment estimated by the recruitment-to-inflation ratio in acute respiratory distress syndrome. A clinical trial. Am J Respir Crit Care Med 201(2):178-187. https://doi.org/10.1164/rccm.20190 2-03340C
12. Grieco DL, Anzellotti GM, Russo A, Bongiovanni F, Costantini B, D'Indinosante M, Varone F, Cavallaro F, Tortorella L, Polidori L, Romano B, Gallotta V, Dell'Anna AM, Sollazzi L, Scambia G, Conti G, Antonelli M (2019) Airway closure during surgical pneumoperitoneum in obese patients. Anesthesiology 131(1):58-73. https://doi.org/10.1097/ALN.0000000000 002662

13. Vimpere D, Coudroy R, Aissaoui N, Younan R, Bailleul C, Couteau-Chardon A, Lancelot A, Guerot E, Chen L, Brochard L, Diehl JL (2020) Influence of obesity on respiratory mechanics in patients with acute respiratory distress syndrome. Anesthesiology (in revision)

14. Borges JB, Costa EL, Suarez-Sipmann F, Widstrom C, Larsson A, Amato M, Hedenstierna G (2014) Early inflammation mainly affects normally and poorly aerated lung in experimental ventilator-induced lung injury*. Crit Care Med 42(4):e279-287. https://doi.org/10.1097/CCM.0000000000 000161

15. Tsuchida S, Engelberts D, Peltekova V, Hopkins N, Frndova H, Babyn P, McKerlie C, Post M, McLoughlin P, Kavanagh BP (2006) Atelectasis causes alveolar injury in nonatelectatic lung regions. Am J Respir Crit Care Med 174(3):279-289. https://doi.org/10.1164/rccm.200506-10060C 